\title{
Entre la tradición y la modernidad: las parejas españolas de doble ingreso
}

\section{Sandra Dema Moreno}

Universidad de Oviedo. Área de Comercialización e Investigación de Mercados Campus del Cristo, s/n. 33006 Oviedo (Asturias)

demasandra@uniovi.es

\section{Resumen}

La participación social de las mujeres, sobre todo su incorporación al mercado de trabajo, es uno de los cambios sociales más significativos de las últimas décadas. Sin embargo, a pesar de la vinculación que existe entre la situación de las mujeres dentro y fuera de la familia, apenas hay investigaciones que nos permitan conocer si han variado y cómo lo han hecho las relaciones de género en el ámbito privado. Este artículo se centra en entender cómo se construyen las parejas modernas y con qué obstáculos se encuentran a la hora de poner en práctica formas de relación igualitarias.

Palabras clave: género, familia, parejas de doble ingreso, poder, igualdad.

\section{Abstract. Between Tradition and Modernity: Dual-Income Spanish Couples}

The participation of women in social life, in particular their incorporation into the labour market, has been one of the more significant changes in the last decades. Although there is a link between the situation of women inside and outside the family, not enough research has been done to allow us to know if these changes in the public sphere are transferred to the private one. This paper tries to discover how modern couples build up their relationships and which are the obstacles to establish egalitarian couples.

Key words: Gender, family, dual-income couples, power, equality.

\section{Sumario}

\section{Metodología 3. Las parejas más igualitarias}

1. Las relaciones de pareja legitimadas por la socialización de género tradicional

2. Las parejas en las que contrasta el ideal igualitario con la realidad cotidiana
Conclusiones

Bibliografía 
En las últimas décadas se ha producido una modificación importante de las relaciones de género en el ámbito público. Las mujeres han accedido de forma generalizada a la educación; en menor medida también han accedido al trabajo remunerado y a la política. Sobre la participación de las mujeres en los campos mencionados hay numerosas investigaciones y publicaciones (Marina Subirats y Cristina Brullet 1988; Judith Astelarra 1990; M. Ángeles Durán 1972 y 1986, por señalar sólo unas pocas). A pesar de que la discriminación laboral, política y social de las mujeres aún continúa, los cambios a los que nos referimos, producidos básicamente en el ámbito público, han supuesto una indudable mejora en la situación de las mujeres.

Sin embargo, no conocemos hasta qué punto la relativa «igualdad» sociolaboral de varones y mujeres se traduce en una situación doméstica igualitaria. He tratado de responder a esta cuestión analizando parejas con dos salarios, aquellas que potencialmente podrían ser más igualitarias, puesto que varones y mujeres tienen trabajo y, por tanto, ingresos propios. El vínculo entre las relaciones de pareja y el dinero no es nuevo para las investigaciones sociales, ya que desde los años 60 con las teorías de Blood y Wolfe se inicia toda una tradición sociológica que examina la relación entre el dinero y el poder en el hogar (Robert Blood y Donald Wolfe 1960; Jan Pahl 1980; Rosanna Hertz 1988; Peper Schwartz 1994; Viviana Zelizer 1997). En este artículo trato de mostrar que la correlación entre ingresos y poder que encontraron Blood y Wolfe no es tan evidente. Las desigualdades entre los miembros de la pareja no parece que estén directa y exclusivamente ligadas con los recursos que gana cada uno de ellos o con otras variables tales como la edad o el nivel educativo, sino que hay otros elementos implicados.

\section{Metodología}

Para la elaboración de este artículo he analizado las entrevistas realizadas en España en el marco de una investigación internacional recién finalizada. ${ }^{1} \mathrm{La}$ selección de las parejas a entrevistar, así como el guión de entrevista seguido, se elaboró en común a los cuatro países participantes en la investigación -España, Alemania, Suecia, Estados Unidos — con el fin de garantizar la comparabilidad.

Durante los años 2001 y 2002 realizamos en nuestro país 51 entrevistas en profundidad a 17 parejas, de las cuales he analizado 39 correspondientes a

1. Investigación en la que participé desde 1999 junto con otras tres profesoras de la Universidad de Oviedo, Capitolina Díaz Martínez, Cecilia Díaz Méndez y Marta Ibáñez Pascual, y junto con investigadores/as de la Universidad Ludwig Maximilian (Alemania), de la Universidad Carnegie Mellon, de la Universidad de Pittsburg (EE.UU.) y de la Universidad de Umea (Suecia). En el proyecto internacional se trataba de analizar la relación entre el dinero, la pareja y la individualización en los 4 países de origen de los/as investigadores/as, caracterizados por tener diferentes modelos de Estados de bienestar. Como parte de este proyecto, he realizado mi tesis doctoral, «La desigualdad y las relaciones de poder en el ámbito privado. Análisis de las parejas con dos ingresos desde una perspectiva de género» (Sandra Dema Moreno 2004), dirigida por Capitolina Díaz, a la que agradezco además la revisión de este artículo. 
parejas de doble ingreso. ${ }^{2}$ Las entrevistas recogen toda la variedad de relaciones salariales posibles entre el varón y la mujer, de tal manera que hemos entrevistado a parejas muy igualadas en sus recursos, así como a parejas en las que las mujeres tienen más recursos que los varones y viceversa. Además de los ingresos de las personas entrevistadas, se han tomado en cuenta otras variables; así hemos entrevistado parejas sin hijas/os y con hijas/os, con el fin de observar la influencia, si la hay, de los/as hijos/as en la vida de la pareja. En función de la duración de la relación, seleccionamos a dos categorías de parejas, aquéllas que llevan menos de cinco años de relación (relaciones de nueva creación) y aquéllas que llevan más de 10 años de relación (parejas consolidadas). $Y$ en función de la edad de los cónyuges diferenciamos dos grupos, los que tienen entre 20 y 39 años y entre 40 y 60. Se restringe el análisis a parejas urbanas de clase media, entendiendo clase media en un sentido muy laxo, de tal manera que las personas entrevistadas cubren una gran variedad de empleos, salarios y niveles educativos.

Una vez definidos los criterios de selección de las parejas, la búsqueda de las mismas se hizo con la técnica de «bola de nieve». Las entrevistas se realizaron en tres etapas. En primer lugar, se entrevistó a los dos miembros de la pareja juntos para, después de un somero análisis de dicha entrevista, realizar, unas semanas más tarde, otra entrevista por separado a cada uno de los cónyuges. Estas segundas entrevistas se prepararon con la información que habían vertido en la entrevista conjunta. ${ }^{3}$

En el marco del proyecto internacional se elaboró un guión de entrevista en el que se abordan numerosos aspectos de la vida de las personas. Tanto la entrevista a la pareja como la individual se inician con una narración biográfica. Las personas entrevistadas generan una narración constructiva en la que nos relatan su vida. ${ }^{4}$ La parte inicial de la entrevista tiene como objeto conocer los aspectos sociales, económicos, culturales y otros aspectos vivenciales que han

2. Aunque las parejas de doble ingreso no son las mayoritarias en España, son un colectivo que ha aumentado en los últimos años y que se supone seguirá aumentando. De hecho, en la década de los 90 las parejas de doble ingreso han aumentado de forma significativa. En 1992 este tipo de parejas representaban un tercio del total de hogares formados por personas entre 20 y 59 años, mientras que en el 2000 alcanzan ya el 45\% de los hogares españoles (Ana Franco y Karin Winqvist 2002).

3. Las entrevistas a las parejas fueron realizadas por las cuatro investigadoras del proyecto ayudadas por un investigador varón. En las entrevistas individuales las investigadoras entrevistaron a la mujer de la pareja y el entrevistador al varón. Otras investigaciones previas a la nuestra muestran la conveniencia de realizar entrevistas por separado a varones y mujeres. Lillian Rubin, en su investigación sobre las familias de clase obrera, se dio cuenta de que las mujeres hablaban de sus sentimientos, de sus vidas y de su matrimonio de una forma más libre si los varones no estaban presentes (Lillian Rubin 1976: 9-11).

4. En la entrevista a la pareja, esta parte inicial se centra en la historia de la pareja vista e interpretada por los propios entrevistados, mientras que en las entrevistas individuales la narración se centra en la vida de cada miembro de la pareja. En la entrevista de pareja, la narración tiene el interés añadido de que los dos cónyuges se complementan mutuamente en la reconstrucción memorística de su pasado común. 
podido influir en la construcción de la personalidad social de cada individuo y de la propia relación de pareja.

A la parte narrativa o biográfica le sigue otra que nos permite averiguar el significado del dinero para las personas entrevistadas. Asimismo, recabamos información acerca de los acuerdos que la pareja tiene establecidos sobre la organización económica del hogar, la toma de decisiones y el control del dinero y sobre las prácticas individuales de uso del dinero. Preguntar a las personas entrevistadas sobre estos temas tiene por objeto conocer el papel que juegan los aspectos económicos en la relación de pareja.

Pero en las entrevistas no nos limitamos a indagar acerca de las cuestiones económicas. Se tratan otros asuntos relacionados con la vida de la pareja, tales como el empleo, el trabajo doméstico, el ocio, la amistad, las relaciones con la familia de origen y los/as hijos/as. Al final de la entrevista se abordan aspectos más íntimos, como la propia relación de pareja, incluyendo algunas preguntas sobre sus relaciones sexuales. ${ }^{5}$ La entrevista concluye con unas preguntas estandarizadas donde se examina con detalle la situación económica de la pareja y, por último, se recogen una serie de datos sociodemográficos que nos ayudarán a enmarcar el conjunto de la entrevista.

La metodología seguida en el análisis de las entrevistas se corresponde, en alguna medida, con lo que Rosemary Crompton (2001) y Charles Ragin (1987 y 1994) definen como estudio comparado de caso - comparative case study approach. Esto es, con el fin de mantener la integridad de la pareja como un todo, analizamos cada pareja por separado como un caso. En un primer momento, se leyeron y releyeron las tres entrevistas que componen cada caso - a la pareja, al marido y a la mujer - una y otra vez hasta lograr tener una idea global del funcionamiento de cada pareja. Una vez analizadas todas las parejas se procedió a la comparación sistemática de las mismas, contrastando las similitudes y diferencias entre las distintas parejas. Esta comparación nos ha llevado a identificar tres tipos de parejas, que revelan diferentes formas de desigualdad y diferentes modos de afrontar las relaciones de poder en la pareja.

Las parejas entrevistadas se encuentran en un momento de transición a la modernidad. Entre las parejas españolas aparecen dos modelos ideales, la pareja tradicional y la pareja simétrica. El ideal de pareja simétrica está en ascenso y la mayor parte de las parejas que hemos entrevistado se inclinan por el mismo. Aunque el ideal de pareja tradicional sigue siendo socialmente respetado, sobre todo en el caso de parejas de cierta edad.

Las parejas de doble ingreso no conforman un bloque homogéneo, sino que podemos diferenciar tres tipos mayoritarios, que se sitúan en un continuo, desde las formas de relación más tradicionales hasta las más igualitarias.

5. Aunque la finalidad de la investigación es averiguar el vínculo entre el dinero y las relaciones de poder en la pareja, la información sobre estos otros aspectos relacionados con la vida privada de las personas entrevistadas puede ayudarnos a comprender mejor los objetivos centrales de nuestra investigación. 
En primer lugar, estarían aquellas parejas en las que se establecen relaciones de poder y de desigualdad legitimadas por la tradicional socialización de género. En segundo lugar, las parejas con ideal igualitario, en las que a pesar del ideal se dan relaciones de poder y desigualdad, que unas veces se manifiestan abiertamente y otras permanecen de forma oculta o latente, pero operante. Y, por último, las parejas que establecen formas de relación más igualitarias y buscan activamente el equilibrio en las relaciones de género.

Los resultados de la investigación muestran que no hay una correlación evidente entre los mayores ingresos de las mujeres y el equilibrio de poder en el hogar. El hecho de que las mujeres tengan dos ingresos, y que algunas de ellas ganen más que sus parejas, no significa que compartan en igualdad el rol profesional y el doméstico. A diferencia de las amas de casa, las mujeres que trabajan fuera del hogar pueden realizarse profesionalmente y acceder a cierta independencia económica; sin embargo, no siempre sucede que las mujeres hagan uso de su autonomía personal, profesional y económica. El trabajo remunerado de las mujeres y sus ingresos no generan automáticamente un equilibrio entre los dos miembros de la pareja. Y en muchos casos, además, lleva añadido un considerable aumento de las horas de trabajo de las mujeres que, con frecuencia, se responsabilizan más y realizan la mayor parte del trabajo doméstico y de las tareas de cuidado de las personas dependientes. ${ }^{6}$ De la misma forma no hay una correlación entre la edad de las personas entrevistadas o su nivel de estudios y el equilibrio de poder en el hogar. ${ }^{7}$ La construcción de un modelo de pareja más o menos igualitario es resultado de procesos complejos a los que nos referimos seguidamente.

\section{Las relaciones de pareja legitimadas por la socialización de género tradicional}

En las parejas en las que tanto el varón como la mujer comparten una ideología tradicional y practican un modelo tradicional de relación, el dinero es un instrumento legitimador de la desigualdad, que permite al varón mantener su papel de principal proveedor del hogar, favoreciendo su autonomía personal y su capacidad de gasto, al tiempo que obstaculiza la autonomía de la mujer. El trabajo remunerado de las mujeres apenas altera el dominio masculino en estas parejas. La clave explicativa de por qué parejas con ambos miembros trabajando a tiempo completo acaban insertos en este tipo de relaciones se encuentra fundamentalmente en la tradicional socialización de género de varones y

6. En este aspecto, los resultados de la investigación coinciden con las diferentes encuestas que han sido realizadas en nuestro país sobre el uso del tiempo de varones y mujeres (CIRES 1991 y 1996; Instituto de la Mujer 2002) y con diversos estudios, como los de M. Ángeles Durán (1986 y 1988), Jesusa Izquierdo, Olga del Río y Agustín Rodríguez (1988), Ramón Ramos (1990) y Mariano Álvaro Page (1996).

7. Un análisis detallado de las parejas jóvenes se encuentra en Sandra Dema Moreno y Capitolina Díaz Martínez 2005. 
mujeres. No todas las mujeres son capaces de construir y mantener su independencia en la relación de pareja. De hecho, hay mujeres cuyo objetivo no es ser autónomas, su socialización de género las lleva a querer ser mujeres tradicionales y a comportarse como tales, a pesar de que trabajen fuera de casa las mismas horas que sus maridos y ganen lo mismo que ellos. Es el caso de una de las mujeres que hemos entrevistado, Inés. ${ }^{8}$ Esta mujer, a pesar de haber tenido un trabajo asalariado toda su vida, preferiría ser sólo ama de casa. Su compromiso laboral es vago y circunstancial. ${ }^{9}$ Aunque mientras estuvo soltera, el trabajo le garantizaba un bienestar mayor que el que podría ofrecerle su familia de origen y le daba independencia económica, una vez casada, si el varón hubiera podido proveer todos los recursos para la familia ella habría dejado de trabajar:

INÉS: Si tuviéramos mucho dinero, yo dejaría de trabajar y me dedicaría, pues eso, a hacer cosas aquí, tejería, haría ganchillo o cosería, que siempre me gustó y ahora tengo menos tiempo. [Inés e Iván] ${ }^{10}$

A pesar de ser trabajadora a tiempo completo, esta mujer se autodefine por su rol fundamental de cuidadora, asumiendo la totalidad del trabajo doméstico y de cuidado. El trabajo no le ha permitido convertirse en una mujer autónoma, debido al peso de su socialización de género. Por el contrario, ha supuesto una doble carga, ya que además de realizar su trabajo remunerado a tiempo completo ha asumido en su totalidad los roles tradicionales de ama de casa.

En este caso, estamos ante un claro ejemplo del valor simbólico del trabajo y del dinero del varón. A pesar de que tanto el hombre como la mujer trabajan las mismas horas ${ }^{11}$ y ganan salarios similares, el trabajo y los ingresos de la mujer no producen una modificación de roles en la pareja. La mujer hizo estudios universitarios y se profesionalizó como medio de salir de su pobre origen familiar, pero las condiciones del entorno tradicional eran tan fuertes que el trabajo remunerado no la ha llevado a cuestionarse su identidad de mujer tradicional. El varón es considerado el principal proveedor del hogar y, en consecuencia, la aportación de la mujer queda desvalorizada.

Esta mujer responde a un modelo de mujer tradicional que no logra ser un sujeto autónomo, sino que se construye de tal manera que es para y de los

8. Tanto el nombre como las profesiones u otros detalles personales han sido cambiados para resguardar la confidencialidad de quienes han sido entrevistados.

9. Bien es verdad que a pesar de la debilidad de su compromiso laboral la mujer se siente orgullosa del trabajo que desempeña y de sus cualidades para realizarlo. Pero, aún así, si la familia pudiera prescindir de su salario ella no trabajaría.

10. Al final de los fragmentos de las entrevistas figuran un nombre o dos nombres propios. Cuando el fragmento corresponde a una entrevista individual al final del mismo aparece el nombre de la persona entrevistada, cuando corresponde a una entrevista de pareja, como en este caso, aparece el nombre de ambos miembros de la pareja.

11. Ambos tienen jornada continua y trabajan de lunes a viernes desde las $7 \mathrm{~h}$. hasta las $15 \mathrm{~h}$. 
otros. ${ }^{12}$ Estas parejas son parecidas a las constituidas por ama de casa y varón proveedor, con una salvedad: las mujeres tienen una mayor autonomía en sus gastos personales, que les da el hecho de ser trabajadoras y no sólo amas de casa. Estas mujeres no tienen que pedir permiso o dar explicaciones para realizar gastos personales o gastos de pequeña cuantía para el resto de la familia o el hogar, pero generalmente se autocontrolan.

La dependencia de la mujer se refleja en los aspectos económicos, ha aprendido desde su infancia a negar sus necesidades y a relegarlas hasta que las necesidades de los varones hubieran sido cubiertas, como podemos ver en la siguiente intervención:

INÉS: No es que haya manejado dinero. Pero bueno, el dinero que había en casa estaba para todos. Cada uno cogía lo que necesitaba. ¿Lo que necesitaba? Bueno, sí. Pero como éramos cinco y cuatro eran varones, pues, claro, los varones siempre tuvieron más. Entonces, bueno, pues llegaba el domingo, un día de fiesta, o lo que fuera y entonces, claro, yo, pues decía: «No, yo me quedo». Porque, después, a lo mejor, hace falta para ir a comprar una medicina o algo... Debe de ser que ya nos mentalizaron así desde pequeñas (risas). [Inés]

En su familia, de origen humilde, anteponía el bienestar de la familia y las necesidades de sus hermanos a las suyas propias. Ahora, que ya no vive en una situación de escasez, sigue aplazando sus necesidades ante las familiares. Se encarga de satisfacer personalmente las necesidades y/o los deseos de su marido e hijos — ambos varones - antes que los suyos. Acepta la autoridad del marido sin cuestionarla y sin que eso se traduzca en conflictos, aunque en ocasiones esté en desacuerdo con las decisiones económicas que se adoptan; de hecho, si por ella fuera serían aún más austeros en los gastos que realizan.

El dinero en este tipo de parejas es un instrumento de poder en manos de los varones, aunque el poder de los varones se mantiene no sólo por su control de los recursos - económicos o de otro tipo-, sino por una combinación de otros elementos. Las normas sociales, la presión social, la costumbre, favorecen que las relaciones de género no se hayan modificado sustancialmente y permiten que los varones sigan estando legitimados para ejercer el poder en la familia, a pesar de que las mujeres trabajen fuera de casa. El poder en este tipo de relación apenas genera conflicto porque es el resultado de una asimilación naturalizada de las relaciones de poder por parte de ambos. Estaríamos ante un ejemplo de lo que Bourdieu denomina dominación simbólica, que consiste en que las mujeres compartan los esquemas mentales que son producto de la dominación. Sus pensamientos y percepciones están estructurados por las propias estructuras de la relación de dominación (Pierre Bourdieu 2000: 22). Y, por tanto, ni siquiera cabe que puedan cuestionar tales estructuras; al contrario, asumen y reproducen las relaciones de poder en las que viven. 


\section{Las parejas en las que contrasta el ideal igualitario con la realidad cotidiana}

En la sociedad española actual se ha producido un cambio favorable a la igualdad en las relaciones de género. De hecho, la mayor parte de las parejas entrevistadas, así como investigaciones cuantitativas más amplias, señalan que la pareja igualitaria es el modelo ideal de relación, ${ }^{13}$ modelo muchas veces compartido por ambos cónyuges. Sin embargo, una cosa es el ideal y otra la realidad, las parejas se enfrentan en su vida cotidiana a numerosos obstáculos que impiden la formación de relaciones igualitarias.

\section{a) El significado del dinero para varones y mujeres}

Ganar dinero y disponer libremente del mismo son condiciones fundamentales para que las mujeres puedan ser autónomas, aunque, como veremos, la posición de las mujeres dentro de la pareja no depende exclusivamente de tener recursos materiales — trabajo y dinero- que antes eran privativos de los varones.

No tener un trabajo que permita a las mujeres una mínima independencia económica es un obstáculo fundamental en la construcción de relaciones igualitarias. Aunque para algunas mujeres el principal impedimento para que se cumpla el ideal igualitario no es sólo la falta de trabajo, sino también la diferencia de recursos. Las mujeres, aún teniendo trabajo, suelen ganar bastante menos que sus maridos y con sus salarios exclusivamente no pueden proveer las necesidades básicas del hogar, con la dependencia que tal situación genera. ${ }^{14}$

En este tipo de parejas, los mayores ingresos de los varones legitiman la desigualdad y el poder masculino. Las mujeres que ganan menos que los varones son vistas como menos proveedoras que ellos, no sólo porque ganan menos dinero, sino porque la familia en muchos casos podría prescindir del salario

13. Una investigación del Instituto Nacional de Estadística realizada a principios de los años 90 señala que el ideal de familia para el 45\% del conjunto de la población española es aquél en el que tanto el varón como la mujer trabajen fuera de la casa y se repartan las tareas del hogar y el cuidado de hijos. El 23\% de la población, por su parte, preferiría un modelo de familia en el que la mujer trabajara fuera del hogar menos horas y se ocupara en mayor medida de las tareas del hogar y del cuidado de hijos. Y sólo para un $27 \%$ de la población, la familia ideal sería aquélla en la que el varón trabajara y la mujer se ocupara en exclusiva de las tareas domésticas y del cuidado de las personas dependientes (Pepa Cruz y Rosa Cobo 1991: 42). Según los datos del Estudio 2481 del CIS, de febrero de 2003, el ideal de familia simétrica ya es compartido por el $64,6 \%$ de la población española, muy por encima de las opciones de pareja donde la mujer trabaje menos horas fuera de casa y se ocupe en mayor medida del hogar y del cuidado de personas dependientes, fórmula ideal para el 17,8\% de la población; o de la alternativa de que el varón sea el único proveedor y la mujer ama de casa, opción respaldada sólo por el $15,8 \%$ de la población.

14. Según la Encuesta de Salarios de la Industria y los Servicios, del IV Trimestre de 2000, la diferencia salarial entre varones y mujeres en nuestro país es de las más elevadas de los países integrantes de la Unión Europea. Las trabajadoras españolas ganan alrededor de un 30\% menos de lo que ganan los varones (INE 2001). 
que ellas ingresan para vivir, pero sobre todo porque los varones detentan la posición de principales proveedores del hogar.

No es lo mismo ganar dinero que considerarse y ser considerado/a en la familia como proveedor/a; esto es, que el trabajo y el dinero de varones y mujeres tengan el mismo valor. Con frecuencia ocurre que los trabajos de las mujeres se ven como accesorios a los masculinos, como secundarios.

Nuestras entrevistas, al igual que las investigaciones de Jean Potucheck, que ha analizado con detalle cómo se construyen los individuos respecto a su trabajo y las relaciones entre el significado del trabajo y la familia, apuntan el vínculo entre la definición de varones y mujeres como proveedores/as y la construcción social del género (Jean Potucheck 1997). Mujeres y varones dan un significado diferente al trabajo; mientras que los varones sienten la obligación de ser proveedores aunque sus mujeres trabajen, las mujeres tienen cierta resistencia a considerarse proveedoras, aunque ganen un salario. Las mujeres trabajadoras no se definen automáticamente como proveedoras, a pesar de que sus salarios sean una parte importante de los ingresos familiares y su principal motivación para trabajar sea la económica (Jean Potucheck 1997: 6).

En aquellas parejas entrevistadas en las que las mujeres ganan menos que los varones, la idea de que quien gana el dinero es su propietario, asociada al papel de principales proveedores del hogar de los varones, les otorga a estos últimos autoridad y legitima su poder ante las mujeres. Impidiendo, a su vez, que las mujeres construyan su autonomía personal y obligándolas a aceptar relaciones desiguales.

El hecho de ser los principales proveedores de la familia hace que, en unos casos, se entienda que los varones son los dueños del dinero y puedan manejarlo en nombre de la familia, independientemente de cuánto dinero ganen, garantizando su autonomía de gasto, como podemos ver en la siguiente intervención:

ELISA: No sé si lo considera él [que el dinero es suyo], pero yo procuro hacérselo saber. El dinero, ya que lo gana él, por lo menos que se lo guarde para sus cosas. [Elisa]

En esta pareja, la mujer gana bastante menos que el varón. ${ }^{15}$ En algunas partes de la entrevista señalan que el dinero es de ambos, pero hay una cierta indefinición acerca de la consideración del dinero como común o privativo de quien lo gana. La pareja vive del salario del hombre, que utilizan para afrontar los gastos cotidianos, pero la mujer sostiene que el dinero que gana el varón es más de él que de ella y, por tanto, puede disponer libremente de ese dinero para gastos personales y aún para sus caprichos. La mujer administra parte de ese dinero, ganado por el varón, el destinado a hacer frente a los gastos cotidianos; sin embargo, le cuesta admitir que es un dinero común, porque choca

15. Los ingresos de la mujer son muy escasos, alrededor de un $20 \%$ de lo que gana el varón. 
con su ideal de ser una mujer independiente, que entiende la relación de pareja como una relación entre iguales. El hecho de que los ingresos de la mujer sean mucho menores que los del varón le impiden a ella considerar el dinero que gana su marido como propio, aunque ambos vivan de ese dinero. Y además, este hecho le lleva a reducir los gastos propios hasta límites exagerados, no sólo porque considera que ese dinero no es suyo, sino también para evitar al máximo la dependencia del varón.

Es frecuente que las mujeres acepten que la diferencia de ingresos o recursos de todo tipo legitima el poder de los varones. Efectivamente, el dinero puede ser una fuente de poder; de hecho, una de las normas sociales más extendidas, en opinión de Burgoyne, es que quien gana el dinero tiene derecho a decidir sobre cómo gastarlo, quien posee el dinero es su propietario/a (Carole Burgoyne 1990). Sin embargo, a pesar de lo que indica esta autora y algunos/as otros/as, nuestras entrevistas nos muestran que la norma de que el dinero es en sí mismo fuente de poder no siempre funciona. En aquellas parejas en las que las mujeres ganan más que los varones, la ecuación mayor dinero $=$ a mayor poder no se cumple. Las mujeres que ganan más que sus compañeros no sólo no transforman sus mayores ingresos en mayor poder, como sería previsible, sino que en ocasiones ni siquiera sus mayores recursos les permiten construir relaciones igualitarias, acordes con su ideal de pareja.

En nuestra opinión, esto es debido al papel de principales proveedores del hogar que todavía detentan los varones en la mayoría de los casos, como rémora del pasado. Los hombres están más cercanos que las mujeres a la idea de ser propietarios de lo que ganan. Por una parte, porque, como decíamos, suelen tener más recursos que ellas, pero también porque han sido educados para ser individuos libres y autónomos y para poseer el dinero y manejarlo sin ningún tipo de prejuicio (Clara Coria 1991). El dinero es un elemento tradicionalmente vinculado a la masculinidad, que ha sustentado el poder y la autoridad de los varones en el hogar.

En los casos en que las mujeres ganan más que los varones y/o tienen trabajos de mayor estatus profesional que ellos no hay razones objetivas que les lleven a la dependencia. Sin embargo, la diferencia de recursos a su favor no les otorga mayor poder. Estas mujeres no se convierten en principales proveedoras del hogar por el hecho de ganar más que sus maridos. Son mujeres que no han renunciado a su autonomía en la relación de pareja, pero tampoco cuentan con el apoyo de sus maridos para desarrollarse personalmente, más bien construyen su autonomía con la oposición de los varones.

Y con frecuencia el dinero se convierte en un obstáculo para la construcción de la igualdad en la pareja. Unas veces, las mujeres que ganan más que sus maridos consienten ciertas relaciones de poder para evitar el malestar de los varones frente a su autonomía económica y/o emocional. Otras veces, es la actuación de los propios varones lo que dificulta la construcción de una relación igualitaria. Esto se da cuando los varones tienen una percepción convencional de la masculinidad, que ven amenazada por el hecho de que las mujeres ganen más, y refuerzan su individualidad sin tener en cuenta o contra los 
principios de la relación de pareja. Algunos varones, al ganar menos que sus esposas, ven cuestionado su rol de proveedores y acaban haciendo que su trabajo y su futuro profesional sean una prioridad de la familia por encima de los de las mujeres. En este contexto varones y mujeres no logran construir relaciones igualitarias y se generan conflictos.

Los varones no pierden su consideración de proveedores en función de lo que ganen. Mantienen su posición en el hogar, de forma que la diferencia de recursos a favor de las mujeres no les desplacen de ser el centro, la referencia de la familia. Los varones que ganan menos que sus mujeres no ven el dinero como menos suyo y no pierden poder, que mantienen de otras formas. Ganar menos o trabajar menos, en principio, no hace que los varones pierdan poder en el hogar. Por el contrario, tanto a ellos como a ellas les crea una dificultad que las mujeres ganen más que los varones y ambos lo disimulan. En la conversación que reproducimos a continuación, vemos cómo uno de los varones entrevistados, a pesar de ganar menos que la mujer, no se considera ni es considerado menos proveedor que ella: ${ }^{16}$

ENTREVISTADOR: ¿Y quién gana más de los dos?

Herminia: Pues de sueldo yo, que estoy a tiempo completo, pero luego, con los ingresos que él tiene, pues seguro que él.

HéCTOR: Con los trabajos sueltos que hago, pues... debemos de estar por el estilo.

Herminia: No, yo creo que ganas más tú. De sueldo hay 600.000 pesetas de diferencia, ahora que lo miramos.

HÉCTOR: Sí, al cabo del año son 600.000 pesetas de diferencia

Herminia: Y tú [con tus trabajos extra] ganas más de eso.

HÉCTOR: Lo que yo gano menos de sueldo, depende del año. Habrá años que gane millón y medio de cosas sueltas y años que gane trescientas mil.

Herminia: Yo creo que ganas más, pero bueno. Más o menos.

HÉCTOR: De todas maneras, como va todo junto al mismo bote. [Herminia y Héctor]

En esta intervención la mujer trata de no dar importancia a la diferencia salarial para disimular delante del varón y delante de las personas entrevistadoras el hecho de que él gana menos que ella, pues los ingresos fijos son los salariales, el resto depende de las actividades extralaborales del varón y es enor-

16. A diferencia de lo que ocurre con las parejas en las que las mujeres ganan menos que sus compañeros y la diferencia salarial es similar a la de este caso - la persona que gana menos percibe en torno a un $80-85 \%$ del salario del cónyuge que gana más. En estas parejas, como decíamos anteriormente, las mujeres tienen claro que el varón es el principal proveedor del hogar y el salario de ellas aparece como secundario. 
memente fluctuante. Ella insiste para que el varón se sienta coproveedor y no proveedor secundario.

Las parejas adoptan estrategias para evitar que el rol de proveedores de los varones se vea cuestionado. Algunas parejas tratan de obviar el hecho, lo disimulan, otras veces son los hombres quienes lo ocultan a las mujeres. La sobrevaloración del salario de los varones o la infravaloración de los gastos que realizan es otra de las tácticas utilizadas para evitar que los varones pierdan su consideración de principales proveedores del hogar. Las formas de sobrevalorar la aportación masculina y minimizar la femenina son variadas. Unas veces, se oculta la diferencia de ingresos, quedando diluida la mayor aportación femenina en la comunidad económica cuando las cuentas son comunes. Otras veces, se tienen cuentas separadas y el dinero se usa para cosas diferentes, con valores también diferentes. ${ }^{17}$

En las parejas en las que las mujeres ganan más que sus maridos, cuando se mantiene cierta separación del dinero, se da más relevancia al salario de los varones haciendo que de ese salario se paguen los gastos más importantes para la familia, como son las grandes compras y los bienes duraderos - la letra del coche o la hipoteca. Mientras que el dinero de las mujeres generalmente sirve para afrontar los gastos cotidianos, en bienes fungibles, que una vez consumidos desaparecen. Es el «domestic money» al que se refiere Zelizer, un dinero especial, construido socialmente e influido por la esfera doméstica en la que circula (Viviana Zelizer 1989: 367-371). Estas parejas utilizan el dinero conforme a roles de género con el fin de mantener el papel de proveedor de los varones.

Una modificación de las condiciones materiales dentro del hogar no lleva a un replanteamiento de las relaciones de género, sino que se establecen los mecanismos necesarios para evitar que los varones pierdan su papel de proveedores del hogar y su autonomía de gasto. Subsisten mecanismos sutiles e informales que hacen que el poder masculino perviva y que tienen mucho que ver con la tradicional socialización de género de varones y mujeres. ${ }^{18} \mathrm{El}$ mantenimiento por parte de los varones del rol de principales proveedores del hogar es una forma de conservar intacta su autoridad en la familia. Dicho mantenimiento está en la base del poder de los varones no sólo en las parejas más tradicionales, sino también en estas parejas en las que el ideal es igualitario.

\section{b) Las alternativas problemáticas}

Pero los elementos que dificultan la construcción de las relaciones igualitarias no están relacionados exclusivamente con los aspectos económicos. Las trayectorias vitales de los individuos que componen las parejas, sobre todo las

17. Verónica Tichenor señala estrategias similares a éstas en sus investigaciones sobre las parejas de doble ingreso (Verónica Tichenor 1999).

18. Uno de esos mecanismos en opinión de Hanne Haavind es el amor. Para esta autora varones y mujeres participan activamente en mantener y ocultar la posición subordinada de las mujeres haciéndola aparecer como expresión del amor (Hanne Haavind 1984: 144). 
formas de funcionamiento que se establecen en los orígenes de la relación, pueden ser determinantes a la hora de que las mujeres se desarrollen como individuos autónomos dentro de la pareja o de que se conviertan en individuos dependientes, a pesar de tener un trabajo remunerado.

Todas las mujeres que hemos entrevistado trabajan y han trabajado desde antes de contraer matrimonio y, salvo en el caso de las mujeres más tradicionales, el trabajo les ha permitido adquirir cierta autonomía, no sólo económica. Sin embargo, muchas de ellas, en un momento dado de la relación, se vieron forzadas a elegir entre su trabajo y la relación de pareja o la familia. A estas elecciones forzosas Ann Oakley las denomina ambivalencia estructural (Ann Oakley 1974) y Katleen Gerson alternativas problemáticas y excluyentes (Katleen Gerson 1985: 123). Son alternativas que encierran una trampa, la elección de cualquiera de ellas tiene consecuencias desfavorables para las mujeres, no así para los varones.

La incorporación de las mujeres al trabajo remunerado no siempre se produce sin conflicto. Las mujeres tratan de combinar el trabajo fuera del hogar con el trabajo dentro del hogar y el cuidado de dependientes, pero muchas veces esta combinación provoca tensiones, puesto que les exige elegir entre opciones antagónicas. La construcción de la identidad autónoma de las mujeres choca con su papel de cuidadoras, lo que con frecuencia les lleva a anteponer la familia a su autonomía personal.

En las entrevistas realizadas aparecen diversos ejemplos de alternativas problemáticas, las mujeres se encuentran con situaciones en las que se ven atrapadas entre sus roles de cuidadoras, esposas y madres y su rol de trabajadoras. Ante tal disyuntiva, suelen dar prioridad a su vida familiar y de pareja, de forma coherente con sus tradicionales roles de género y renunciando así a un mayor grado de autonomía personal. Este tipo de comportamiento se observa sobre todo en las parejas en las que las mujeres ganan menos que sus maridos. La diferencia de ingresos a favor de los varones legitima su poder en la relación e impide que las mujeres puedan construir su autonomía personal, como ellas hubieran querido, haciéndolas dependientes no sólo en el aspecto económico.

Es el caso de una de las mujeres entrevistadas, que al acabar la carrera se fue a vivir a una ciudad bastante alejada de su lugar de origen por razones laborales, al cabo del tiempo renuncia a su empleo de funcionaria para volver junto a su pareja. Lo que vemos en el comportamiento de esta mujer es que valora más el mantenimiento de su relación que el asegurar su independencia económica. Incluso cuando su ideal de pareja es el simétrico, antepone el vivir junto a su pareja, aunque para ello tiene que renunciar a la independencia económica que ya tenía. El varón, por su parte, hizo un intento de búsqueda de trabajo en la ciudad a la que ella se había mudado, pero al no encontrar un trabajo satisfactorio decide volver a su ciudad de origen, dando prioridad a su independencia económica y a su carrera profesional frente a la vida de pareja, justo lo contrario de lo que acaba haciendo la mujer. Estas decisiones iniciales marcan la trayectoria posterior de la relación. 
Las alternativas problemáticas aparecen también en otros ámbitos, como en el caso de la maternidad y el cuidado de los/as hijos/as. La decisión de tener hijos/as es mucho más problemática para las mujeres que para los varones. Las mujeres con hijos y con aspiraciones laborales manifiestan cierta ambivalencia hacia la maternidad. Las mujeres sin hijos, en unos casos, tienen claro que no quieren ser madres por las dificultades que conlleva la maternidad en sus vidas y, en otros, son conscientes de dichas dificultades y esperan poder tenerlos en el futuro, una vez que se hayan insertado en el mercado de trabajo, o que resuelvan otro tipo de circunstancias relacionadas con la pareja, que les dificultan tenerlos aunque hayan logrado una cierta estabilidad laboral.

Muchas mujeres solucionan estas alternativas problemáticas renunciando a su independencia, anteponiendo la pareja o las necesidades familiares a la construcción de su identidad autónoma en un momento decisivo de su relación. Estas mujeres tratan de buscar soluciones individuales a unos problemas que creen individuales, de tal manera que se esfuerzan por conseguir más recursos y más estatus, elementos que ellas consideran que les permitirán salir de la situación de dependencia en la que se encuentran. Otras esperan que algún día podrán permitirse tener ayuda doméstica, y así alguien que no sean ellas pueda encargarse de la realización de las tareas domésticas, o esperan que en un futuro no muy lejano sus hijos/as crezcan y no requieran tantos cuidados.

Aunque en opinión de estas mujeres la situación de desigualdad es momentánea, no es tan fácil que puedan enfrentarse a obstáculos estructurales, como la falta de trabajo o la escasez de políticas públicas. Y menos aún a cuestiones que ni siquiera han identificado como problemáticas, como pueden ser las relacionadas con la socialización de género. Las alternativas problemáticas son difíciles de solucionar individualmente y exigirían una modificación general de las relaciones de género en nuestro país.

Las mujeres consideran que la situación en la que se hallan es provisional, pero la provisionalidad no es tal, puede incluso alargarse por tiempo indefinido. El análisis de las entrevistas realizadas nos revela que las pautas que se establecen en el origen de la relación de pareja son difíciles de modificar, sobre todo cuando llevan a la dependencia de las mujeres. Es complicado que se pueda llegar a establecer una relación igualitaria cuando se inicia en condiciones no igualitarias, ya que las formas de funcionamiento se consolidan y las mujeres acaban resignándose a la desigualdad.

Las mujeres, por una combinación entre la dependencia económica y/o afectiva y la socialización de género, terminan por asumir la división de roles. Usan su tiempo y su energía para que la familia funcione, haciéndose cargo de las responsabilidades de cuidado y de gestión de lo cotidiano, a costa de su autonomía personal y de la correlación de fuerzas en el hogar. Los varones, por el contrario, no suelen enfrentarse a alternativas problemáticas, no se encuentran con la disyuntiva de tener que escoger entre ámbitos tan controvertidos como la pareja o la familia y el trabajo, y en todo caso, elijan lo que elijan no les supone renunciar a su independencia o autonomía. En las entrevistas que 
hemos realizado, encontramos algunos ejemplos de varones que van a vivir a la casa que las mujeres tenían antes de conocerles o que empiezan a trabajar en el negocio que las mujeres ya tenían montado antes de entablar la relación. Estos varones no renuncian a su autonomía por dichas circunstancias. Además, cuando se produce cierta tensión entre la individualidad y la familia generalmente se resuelve de forma no novedosa, anteponiendo los intereses del varón frente a los de la familia, consecuencia de las relaciones de género sexistas existentes en las relaciones de pareja y del escaso replanteamiento de la identidad masculina que encontramos en los varones entrevistados.

En este tipo de parejas en las que se produce una divergencia entre el ideal igualitario y la realidad cotidiana, los varones ejercen o tratan de ejercer el poder y las mujeres no pueden o no saben cómo contrarrestarlo. En unos casos, los varones ejercen el poder activamente; en otros, lo ejercen a través de su inactividad, no implicándose ni en el terreno laboral ni en el doméstico ni en el emocional, más de lo que consideran necesario. El poder, en este modelo de relación de pareja, no es asumido ni asimilado por las mujeres de la misma forma que en el modelo de pareja tradicional y, de hecho, aunque en ocasiones se considere legítimo, su ejercicio no está exento de conflicto, porque choca con el ideal igualitario de la pareja. Las mujeres en estas parejas se encuentran en una situación de conflicto y, en muchos casos, tratan de remediar la disonancia cognitiva que se produce entre el ideal igualitario y la realidad de desigualdad en la que viven con estrategias que justifiquen dicha desigualdad.

\section{Las parejas más igualitarias}

Decíamos antes que podíamos situar los tres tipos de parejas identificados en un continuo. En uno de los extremos estarían las parejas que reproducen relaciones basadas en el poder masculino; en el medio, las parejas en las que contrasta su ideal igualitario con la realidad cotidiana en la que viven y en el otro extremo estarían las parejas más igualitarias, ${ }^{19}$ a las que vamos a referirnos seguidamente. Aunque estas parejas no son las mayoritarias, su estudio adquiere una gran relevancia ya que pueden mostrar las tendencias de las relaciones de género en un futuro próximo.

En la base de la construcción de este modelo de pareja hay un acuerdo, unas veces explícito, otras no, de que las relaciones tienen que ser igualitarias. Las mujeres valoran, tanto o más que su relación de pareja, su autonomía y la igualdad con su marido/compañero.

La construcción de la relación de pareja se negocia y ambos miembros tienen poder para negociar; es decir, ambos miembros se perciben y son percibi-

19. Nos referiremos a estas parejas como aquellas más igualitarias o que tienden a la igualdad y no como igualitarias, ya que a pesar de que en el conjunto de las parejas entrevistadas son las más cercanas a los planteamientos igualitarios, incluso en este tipo de parejas persisten desigualdades de género. 
dos por el otro como iguales. ${ }^{20}$ Las mujeres juegan un papel más activo que los varones en la construcción de este modelo de pareja más igualitario, de hecho, son sus principales artífices. Las mujeres, además de ser las impulsoras de tal negociación, se constituyen en las vigilantes del acuerdo y ponen en práctica todo tipo de mecanismos dirigidos a mantener la igualdad en la pareja.

Los elementos que llevan a las mujeres a optar por un modelo de relación semejante y a encabezar la negociación con sus maridos son variados. Unas veces, es consecuencia de la construcción de su identidad de género, las mujeres son individuos autónomos y quieren mantener dicha autonomía en la relación, no disolverla por vivir en pareja. En otras ocasiones, se da como reacción a una situación anterior de desigualdad, las mujeres han experimentado relaciones pasadas de dominación o saben que el varón con el que conviven estableció relaciones de ese tipo en el pasado y no quieren repetir ese tipo de modelos.

Para que se establezca una forma de relación afectiva que tienda a la igualdad tienen que darse una serie de elementos. En primer lugar, las mujeres tienen que haberse construido como individuos autónomos y lograr mantener su autonomía en la pareja, tienen que ser autónomas personal y afectivamente. El trabajo y el dinero son factores favorecedores de dicha autonomía, como señala claramente una de las mujeres entrevistadas:

MARía: Porque yo creo que lo único que te da independencia es tu trabajo. No es lo de ganarse el pan con el sudor de la frente, es ganarás tu independencia con el sudor de tu frente. [María y Manuel]

Ganar dinero es importante para estas mujeres porque las protege de la dependencia de sus maridos o de sus familias. La mayor parte de las entrevistas analizadas muestran que el trabajo remunerado y el dinero son condiciones indispensables para que las mujeres consigan su autonomía económica y personal. La autonomía económica es un elemento que favorece la personal y ambos tipos de autonomía son dos pilares fundamentales sobre los que se sustentan las relaciones de pareja igualitarias.

Algunas de estas mujeres, ante la clara convicción de la importancia que tiene su autonomía económica en la construcción de su autonomía personal y en el establecimiento de una relación de pareja igualitaria, se afanan por ser

20. Tomando la expresión de Celia Amorós para analizar el ámbito político podríamos decir que estas mujeres han logrado entrar en el «espacio de los iguales». Por espacio de los iguales esta autora entiende «el campo gravitatorio de fuerzas políticas definido por aquellos que ejercen el poder reconociéndose entre sí como los titulares legítimos del contrato social» (Celia Amorós 1987: 121). Las mujeres que estamos analizando en nuestras entrevistas son consideradas como iguales por su pareja y como individuos con capacidad de negociar. A diferencia del resto de mujeres que, usando de nuevo la expresión de Celia Amorós, estarían en el «espacio de las idénticas», aquéllas que no son individuos «individualizados», sino "genéricos», y como tales no dotados de autonomía, ni de poder, ni de capacidad de negociación en el conjunto de sus relaciones de pareja. 
autónomas económicamente. Aunque no sea muy frecuente, estas mujeres, cuando se enfrentan a la alternativa de tener que elegir entre el trabajo y su relación de pareja, no renuncian a su independencia económica. En una de las parejas entrevistadas, justo al inicio de la relación y ante la dificultad de encontrar trabajo en su lugar de origen, la mujer decide irse a otra ciudad alejada. La separación originó un conflicto en la pareja, pero a los pocos meses el varón fue a vivir con ella y al cabo de un tiempo ambos volvieron a su ciudad de origen. Esta mujer se ganó el respeto de su marido al demostrarle que era independiente económicamente y que podía serlo afectivamente; desde el principio, sentó su relación sobre bases de igualdad y trabaja por mantenerlas. Cuando en el comienzo de la relación de pareja se establecen formas igualitarias se crea un precedente que favorece un funcionamiento posterior igualitario.

En estas parejas, a diferencia de las analizadas anteriormente en las que contrastaba el ideal igualitario y la realidad cotidiana, las mujeres logran afirmarse como individuos autónomos y coproveedores en pie de igualdad con los varones. Se ven y son vistas por el varón como proveedoras en igualdad y esta consideración de proveedoras les permite equilibrar la correlación de fuerzas en el hogar y promover activamente el establecimiento de relaciones igualitarias. Esto no significa que las mujeres tengan que ganar lo mismo que los varones, aunque en muchas de estas parejas los recursos están bastante equilibrados $\mathrm{y}$, en algunas de ellas, el hecho de que las mujeres dispongan por sí solas de los recursos suficientes para poder vivir por su cuenta y mantener a sus hijos/as favorece su autonomía económica.

Otro factor fundamental en el establecimiento de una pareja tendente a la igualdad es la no oposición del varón a la autonomía de la mujer y a la igualdad en la relación, aunque no se traduzca en un apoyo activo. Los varones ven a las mujeres como iguales, no se oponen a la construcción de su autonomía y no ejercen el poder en la pareja.

Aún cuando todos estos elementos se den, aparecen obstáculos a la democratización de las relaciones de género, como la socialización de género que dificulta la construcción de la identidad autónoma de las mujeres, la división de tareas domésticas y de cuidado, asumidas con frecuencia por las mujeres, los roles tradicionales de los varones en relación con el dinero, la implicación más activa y continuada de las mujeres para mantener relaciones equilibradas y el desgaste que eso supone, entre otros.

El establecimiento de la autonomía individual se opone al ejercicio por parte de las mujeres, en exclusiva, de sus roles tradicionales de madres y cuidadoras. Los diferentes lazos que ligan a las mujeres con las familias y con los valores de cuidado y los efectos de no tener vida privada dificultan la posibilidad de que puedan establecer unas relaciones en clave singular. La individualización de las mujeres es altruista, si utilizamos la expresión de Singly (François de Singly 2000: 243). De la misma forma, el papel de cuidadoras de las mujeres puede llevarlas a renunciar a oportunidades personales que, a su vez, obstaculizan la construcción de la individualidad en la pareja. Las mujeres, como señalan algunas autoras, practican una ética del cuidado o ética familiar fren- 
te a la ética de la justicia o ética individual de los varones, que estaría basada en el altruismo de las mujeres en el cuidado hacia las y los demás (Nancy Chodorow 1978; Carol Gilligan 1982). Aunque en las mujeres trabajadoras esta ética se combina con la ética del éxito profesional y del triunfo en el medio laboral y económico en el que se encuentran, por lo general, las mujeres se enfrentan a las relaciones íntimas teniendo mayoritariamente presente la ética «altruista» o «de cuidado».

En estas parejas, que se implican activamente en la construcción de relaciones igualitarias, se da una cierta transformación en los tradicionales roles de género de varones y mujeres. Pero, aún así, hay diferencias destacables, las mujeres tratan de combinar el trabajo fuera del hogar, con el trabajo dentro del hogar y el cuidado de dependientes y muchas veces esta combinación les lleva a la tensión de tener que elegir entre las alternativas problemáticas, que antes señalamos. La construcción de la identidad autónoma de las mujeres, incluso de las más igualitarias, choca con su papel de cuidadoras. Los varones, hasta ahora, no han asumido el rol de cuidadores ni las responsabilidades domésticas en la misma medida que las mujeres, por lo que no se les plantean las mismas dificultades que a ellas ni se produce un choque en sus roles de género. Pero, además, los hombres no necesitan construir su identidad autónoma, su autonomía se les supone por el hecho de ser varones. La tradicional socialización de género que en mayor o menor medida han recibido los varones y las mujeres entrevistados/as no sólo dificulta la construcción de la autonomía femenina, sino que además les exige a estas últimas una mayor implicación en el establecimiento y el mantenimiento de unas relaciones de pareja tendentes a la igualdad.

\section{Conclusiones}

En las parejas de doble ingreso se generan unas formas de relación que hacen que las desigualdades se mantengan incluso cuando las mujeres trabajan fuera del hogar y ganan su propio dinero. En las parejas que calificamos de más tradicionales, las relaciones de poder y las desigualdades de género forman parte del propio modelo de relación. Unas y otras se encuentran integradas y legitimadas para varones y mujeres; por tanto, este tipo de funcionamiento no suele producir conflictos.

Pero, como decíamos, las parejas tradicionales están dando paso a otros modelos de relación más igualitarios, al menos en teoría. La mayor parte de las parejas entrevistadas comparten un ideal de relación simétrico y, sin embargo, el ideal no siempre se ve reflejado en la práctica, debido a los numerosos obstáculos que dificultan y, en ocasiones, impiden que las parejas logren un funcionamiento igualitario en su vida cotidiana.

Las mujeres se enfrentan a relaciones de pareja en las que los varones son quienes dan el significado a las cosas, en las que ellos son el centro de la familia y sus intereses se convierten en los intereses familiares; en definitiva, el poder masculino se encuentra legitimado. En esta situación de desigualdad, las muje- 
res luchan activamente por construir un tipo de relaciones simétricas, convirtiéndose en las artífices de los principales cambios en el hogar y en sus parejas. Pero no siempre consiguen generar tales cambios y el desgaste que supone hace que muchas de ellas renuncien a asumir tales responsabilidades.

El desajuste entre el ideal igualitario y la realidad desigual provoca malestar en estas mujeres y se expresa a través de conflictos en la pareja, unas veces explícitos y otras encubiertos, pero además genera en las mujeres sentimientos de resignación parcial y de amargura, así como deseos de rebeldía oculta.

Los obstáculos para el establecimiento de relaciones igualitarias son muchos, pero aún así algunas parejas, con el esfuerzo decidido de las mujeres, logran adoptar pautas de funcionamiento que tienden a la simetría y tratan de establecer formas de relación no convencionales. Sin embargo, se generan fuertes tensiones, por una parte por el intento de consolidar nuevas formas de relación y, por otra, por la situación social de discriminación de las mujeres y la tradicional socialización de género, que sitúan a las mujeres en una posición de partida subordinada. Estos obstáculos ralentizan la construcción de la igualdad en la pareja y nos llevan a afirmar que aunque el ideal predominante sea la igualdad de sexos, en la práctica las estructuras de desigualdad y las relaciones de poder son omnipresentes. De hecho, encontramos relaciones de poder incluso entre las parejas más jóvenes, en aquellas que muestran una clara conciencia igualitaria, o en aquellas otras en las que no se dan circunstancias objetivas que lo pudieran justificar.

El poder social de los varones conforma un sistema de relaciones de pareja que lo envuelve todo. Las normas sociales, los valores asociados a la feminidad y a la masculinidad hacen que varones y mujeres se sitúen en posiciones diferenciadas y jerarquizadas, que se manifiestan en las relaciones en el interior del hogar y que perpetúan la posición minorizada de las mujeres tanto en el ámbito público como en el privado.

\section{Bibliografía}

Álvaro Page, Mariano (1996). Los usos del tiempo como indicadores de la discriminación entre géneros. Madrid: Instituto de la Mujer.

Amorós, Celia (1987). «Espacio de los iguales, espacio de las idénticas. Notas sobre poder y principio de individuación». Arbor 503-504: 113-127.

AstelarRa, Judith (comp.) (1990). Participación politica de las mujeres. Madrid: Centro de Investigaciones Sociológicas.

BloOD, Robert; Wolfe, Donald (1960). Husbands and Wives. Nueva York: Free Press. Bourdieu, Pierre ([1998] 2000). La dominación masculina. Barcelona: Anagrama. Burgoyne, Carole B. (1990). «Money in Marriage: How Patterns of Allocation Both Reflect and Conceal Power». The Sociological Review 38 (4): 634-665.

CHOdorow, Nancy (1978). The Reproduction of Mothering. Berkley: University of California Press.

Coria, Clara (1991). El sexo oculto del dinero. Barcelona: Ediciones Paidós.

Crompton, Rosemary (2001). "Gender, Comparative Research and Biographical Matching». European Societies 3 (2): 167-190. 
Cruz Cantero, Pepa; Cobo Bedía, Rosa (1991). Las mujeres españolas: Lo privado y lo público. Madrid: CIS.

Dema Moreno, Sandra (2004). La desigualdad y las relaciones de poder en el ámbito privado. Análisis de las parejas con dos ingresos desde una perspectiva de género. Oviedo: Servicio de Publicaciones de la Universidad de Oviedo. [Formato CD.]

Dema Moreno, Sandra; Díaz Martínez, Capitolina (2005). "La construcción de la igualdad en las parejas jóvenes: de los deseos a la práctica cotidiana». INJUVE 67.

DurÁN, M. Ángeles (1972). El trabajo de la mujer en España: Un estudio sociológico. Madrid: Tecnos.

- (1986). La jornada interminable. Icaria: Barcelona.

- (1988). De puertas adentro. Madrid: Instituto de la Mujer.

Franco, Ana; WinQVist, Karin (2002). «Women and Men Reconciling Work and Family Life». Statistics in focus. Population and Social Conditions. European Communities, Eurostat.

Gerson, Kathleen (1985). Hard Choices: How Women Decide About Work, Career and Motherhood. Berkeley: University of California Press.

Gilligan, Carol (1982). In a Different Voice. Psichological Theory and Women's Development. Cambridge, Massachusetts, Londres: Harvard University Press. HaAvind, Hanne (1984). «Love and Power in Marriage». En HolTER, Harriet (ed.) (1984). Patriarchy in a Welfare Society. Oslo: Universitetsforlaget, p. 136-167. HerTZ, Rosanna (1988). More Equal than Others. Berkeley: University of California Press.

Holter, Harriet (ed.) (1984). Patriarchy in a Welfare Society. Oslo: Universitetsforlaget.

InSTITUTO DE LA MUJER (2002). La mujer en cifras. [Disponible en: www.mtas.es/ mujer/mcifras]

InSTITUTO NACIONAL de Estadística (2001). Encuesta de salarios de la Industria y los servicios. IV trimestre del 2000. [Disponible en: www.ine.es.]

IzQUiERDO, Jesusa; Río, Olga del; RodrígueZ, Agustín (1988). Las desigualdades de las mujeres en el uso del tiempo. Madrid: Instituto de la Mujer.

LAGARDE, Marcela (2001). "Identidad Femenina». CENDOC-CIDHAL Lecturas y Noticias. Mayo 2001. [Disponible en: http://www.laneta.apc.org/cidhal/lecturaliden tidad/texto3. htm]

OAKLeY, Ann (1974). Woman's Work: The Housewife, Past and Present. Londres: Allen Lane.

PAHL, Jan (1980). «Patterns of Money Managment Within Marriage». Journal of Social Politics 9 (3): 315-335.

POTUCHEK, Jean (1997). Who Supports the Family? Gender and Breadwinning in DualEarner Families. Stanford: Stanford University Press.

Ragin, Charles (1987). The Comparative Method. Berkeley, Los Angeles: University of California Press.

- (1994). Constructing Social Research: The Unity and Diversity of Method. Thousand Oaks: Pine Forge Press.

Ramos TORRes, Ramón (1990). Cronos dividido: uso del tiempo y desigualdad entre hombres y mujeres en España. Madrid: Instituto de la Mujer.

RuBIN, Lillian (1976). Worlds of Pain: Life in the Working-Class Family. Nueva York: Basic Books.

SCHWARTZ, Pepper (1994). Love Between Equals: How Peer Marriage Really Works. Nueva York: The Free Press. 
SingLY, François de (2000). Libres ensemble. Lindividualisme dans la vie commune. París: Editions Nathan.

SubIRATS, Marina; BRULLET, Cristina (1988). Rosa y azul: la transmisión de los géneros en la escuela mixta. Madrid: Instituto de la Mujer.

ZELIZER, Viviana A. (1989). "The social meaning of money: "Special monies"». American Journal of Sociology 95: 342-377.

- (1997). The Social Meaning of Money. Princeton University Press. 